\title{
Diversidade de Gluconacetobacter diazotrophicus isolada de plantas de cana-de-açúcar cultivadas no Brasil
}

\author{
Liamara Perin ${ }^{(1)}$, José Ivo Baldani(2) e Veronica Massena Reis(2)

\begin{abstract}
(1)Universidade Federal Rural do Rio de Janeiro, Instituto de Agronomia, Km 47 da BR 465, CEP 23890-000 Seropédica, RJ. E-mail: liaperin@yahoo.com.br (2)Embrapa Agrobiologia, Km 47 da BR 465, CEP 23890-000 Seropédica, RJ. E-mail: ibaldani@cnpab.embrapa.br, veronica@cnpab.embrapa.br
\end{abstract}

\begin{abstract}
Resumo - O objetivo deste trabalho foi avaliar a diversidade da população de Gluconacetobacter diazotrophicus oriunda de cultivares de cana-de-açúcar (Saccharum spp.) de diferentes regiões e bancos de germoplasma. O estudo foi realizado com 123 isolados, obtidos de folhas, colmos e raízes de 80 espécies e híbridos de cana-deaçúcar, procedentes de diferentes países e mantidos em coleções de germoplasma nos Estados da Bahia e Rio de Janeiro. Foram utilizados cinco isolados obtidos de plantas de café (Coffea arabica), dois de abacaxi (Ananas comosus) e um de Pennisetum purpureum e mais 10 estirpes com padrões eletroforéticos distintos, após o uso de enzimas comuns do metabolismo microbiano (MLEE). O agrupamento obtido por meio da técnica de imunoadsorção com enzima acoplada (ELISA) sugere que as variações expressas pelos isolados não estão relacionadas com a espécie de planta, a variedade de cana-de-açúcar, a origem geográfica, a parte da planta de onde os isolados foram obtidos e o tempo de amostragem. Altas doses de nitrogênio levaram à diminuição da diversidade de G. diazotrophicus.
\end{abstract}

Termos para indexação: ELISA, fixação biológica de nitrogênio, bactérias endofíticas.

\section{Diversity of Gluconacetobacter diazotrophicus isolated from sugarcane plants cultivated in Brazil}

\begin{abstract}
The objective of this study was to evaluate the diversity of Gluconacetobacter diazotrophicus isolates from different sugarcane (Saccharum spp.) varieties. This study was developed using 123 strains from the internal tissues of stems and roots, isolated from 80 species and hybrids of sugarcane, originated from different countries and maintained in two germoplasm collections localized in Bahia and Rio de Janeiro States. Five isolates obtained from coffee plants (Coffea arabica), two from pineapple (Ananas comosus), one from Pennisetum purpureum and 10 strains, which present different electrophoretic patterns, were used in the comparison. Cluster analysis of enzyme-linked immunosorbent assay (ELISA) results suggested that variations were not correlated with the plant species, sugarcane variety, geographic origin, parts of plants nor with sampling time. High nitrogen doses lowered the diversity of G. diazotrophicus.
\end{abstract}

Index terms: ELISA, biological nitrogen fixation, endophytic bacteria.

\section{Introdução}

Além de fixar nitrogênio atmosférico, Gluconacetobacter diazotrophicus (Cavalcante \& Dobereiner, 1988) produz hormônios de crescimento, como o Ácido Indol Acético (AIA) (Fuentes-Ramírez et al., 1993), é tolerante a vários antibióticos, como estreptomicina, tetraciclina e rifampicina (Muthukumarasamy et al., 2002), ampicilina, erytromicina e roxitromicina (Mowade \& Bhattachayya, 2000, citado por Muthukumarasamy et al., 2002), e possui atividade antagonista a Xanthomonas albilineans
(Piñon et al., 2002) e ao fungo Colletotrichum falcatum (Muthukumarasamy et al., 2000). A diversidade genética dessa bactéria diazotrófica, avaliada pela técnica de uso de enzimas comuns do metabolismo microbiano (MLEE), foi baixa (Caballero-Mellado \& MartínezRomero, 1994; Caballero-Mellado et al., 1995).

A técnica de ELISA (enzyme linked immunosorbent assay) tem sido amplamente utilizada em trabalhos de ecologia microbiana na detecção tanto de viroses (Lommel et al., 1982) quanto de rizóbio (Ribeiro, 1999). Recentemente, Silva (1999) utilizou a técnica de ELISA indireta no estudo da colonização de bactérias 
diazotróficas em cana-de-açúcar e Reis Júnior et al. (2004) no estudo da diversidade destes microrganismos colonizando espécies de Brachiaria spp.

Ribeiro (1999) utilizou a técnica de ELISA para agrupar isolados de rizóbio de Caupi (Vigna unguiculata) da Região Nordeste brasileira, tendo como parâmetro a semelhança com a estirpe padrão de Bradyrizobium.

Stephan et al. (1995), estudando polissacarídeos capsulares associados à superfície celular de G. diazotrophicus, através da técnica de ELISA, verificaram que este microrganismo apresentava variação na estrutura da parede celular, e propuseram a classificação em quatro grupos, com base na presença de açúcares neutros. Assim distinguiram cápsulas com fucose, cápsulas ricas em manose, cápsulas com alta relação hexose/desoxiexose e cápsulas com baixa relação hexose/desoxiexose. A sensibilidade da técnica, atestada pela capacidade de distinção de compostos da parede celular, respalda seu uso no estudo de diversidade do G. diazotrophicus.

O objetivo deste trabalho foi avaliar a diversidade da população de G. diazotrophicus oriunda de cultivares de cana-de-açúcar (Saccharum spp.) de diferentes regiões e bancos de germoplasma.

\section{Material e Métodos}

Foram testados 140 isolados e padrões de G. diazotrophicus retirados de colonização natural de plantas de cana-de-açúcar, café, abacaxi e Pennisetum purpureum, sendo 71 da parte aérea e 69 do sistema radicular. Destes, 81 foram isolados de 50 variedades de cana-de-açúcar, originárias de 15 países e mantidas no banco de germoplasma da Cooperativa dos Produtores de Açúcar e Álcool do Estado de São Paulo (Copersucar), localizado em Camamu, BA, e mais 42 isolados de 30 variedades de cana-de-açúcar provenientes do banco de germoplasma da Empresa de Pesquisa Agropecuária do Estado do Rio de Janeiro (Pesagro), em Campos dos Goytacazes, RJ. Foram incluídos aos 123 isolados de cana-de-açúcar, cinco isolados de G. diazotrophicus retirados de plantas de café e dois de abacaxi, cultivados no México (TapiaHernandez et al., 2000; Fuentes-Ramírez et al., 2001), e 10 estirpes dos diferentes padrões eletroforéticos obtidos pelo uso de enzimas comuns do metabolismo microbiano: PAL5, PAL3, PPE-4, PRJ2, PRJ14, PSP17, PSP32, CFNE550 e CFNE 501, e PRC1.

Na realização do ELISA indireto, foram utilizados antisoros contra as estirpes padrões PAL3 e PRJ2
(Silva, 1999) e mais três anti-soros produzidos contra a estirpe PAL5, isolada de cana-de-açúcar (Cavalcante \& Dobereiner, 1988), PRC1, isolada de Pennisetum purpureum (Reis et al., 1994), e UAP-Ac7, de abacaxi (Tapia-Hernandez et al., 2000), conforme Reis et al. (1997). Amostras de sangue dos coelhos foram coletadas antes da primeira imunização (pré-imune) e após a terceira (parcial) e a oitava imunização (final). $\mathrm{O}$ anti-soro foi posteriormente purificado utilizando colunas contendo Proteína A (Hi-Trap - BioRad), conforme metodologia descrita por Reis et al. (1997).

A especificidade dos anticorpos produzidos foi avaliada testando os anti-soros contra outras estirpes de microrganismos diazotróficos da própria espécie e de gêneros e espécies de microrganismos diazotróficos associados à cana-de-açúcar crescidos no mesmo meio de cultura SYP (Caballero-Mellado \& Martínez-Romero, 1994) (Tabela 1). Para tanto, os microrganismos-alvo foram colocados numa placa de ELISA, ajustados com densidade ótica correspondente a $10^{8}$ células $\mathrm{mL}^{-1}$. Utilizou-se a técnica de ELISA indireta em todos os ensaios de caracterização dos anticorpos produzidos, seguindo o protocolo de Reis et al. (1997).

Os valores de densidade ótica obtidos pela técnica de ELISA indireta da reatividade dos isolados com os antisoros produzidos foram transformados em porcentagem, e seus valores relacionados com o controle positivo da reação, ou seja, reação da estirpe que deu origem ao soro com seu respectivo soro, que foi considerado $100 \%$. Os valores transformados foram associados por meio de análise de agrupamento pelo programa NTSYS (Rohlf, 2000), índice de Bray Curts e método pela associação média UPGMA (Método da Média Aritmética Não Ordenada).

Os isolados que apresentaram maior distância de agrupamento na reatividade imunológica pelo teste de ELISA foram selecionados para amplificação gênica com os primers AD, L927Gj e L923Ga, espécie-específicos para G. diazotrophicus (Kirchhof et al., 1998), G. johannae e G. azotocaptans (Fuentes-Ramírez et al., 2001), respectivamente. Para extração de DNA, foi utilizado o método de lise alcalina das células, conforme Audy et al. (1996).

\section{Resultados e Discussão}

As amostras pré-imune e parcial foram diluídas até 1:10.000 e verificou-se que todos os anticorpos produzidos apresentaram aumento do reconhecimento dos antisoros com os isolados que lhes deram origem após a terceira imunização. Estes resultados indicaram que 
estava ocorrendo produção de anticorpos contra os antígenos alvo, portanto foi dada continuidade às inoculações.

Após a sétima inoculação, realizou-se novamente o teste de diluição visando verificar se a produção de anticorpos já tinha atingido valores considerados ótimos, aumentando o número de diluições até 1:20.000. Em todos os casos, observou-se maior densidade ótica com o aumento do número de imunizações, porém estes aumentos variaram entre os antígenos, provavelmente por causa das diferenças na capacidade antigênica ou da resposta do animal, semelhante aos resultados de Reis et al. (1997) e Silva (1999).

A especificidade foi determinada por meio de testes de reação cruzada contra bactérias diazotróficas de diversos gêneros e espécies (Tabela 1). Inicialmente, foram testados os anti-soros brutos e, visando diminuir as inespecificidades, foram novamente testados após purificação em colunas contendo proteína A.

Segundo Gray \& Mansoor (1996), o pré-requisito para o uso de métodos sorológicos nos estudos de diversidade é a informação sobre a especificidade do antisoro, avaliada em relação à taxonomia entre os organismos testados. Os anti-soros produzidos neste trabalho foram específicos em relação às estirpes de G. diazotrophicus testadas, e todas foram reconhecidas, porém em intensidade variada (Figuras 1, 2 e 3).
Quando as estirpes do ensaio imunológico foram usadas como antígeno para produção de anticorpos, observou-se alta taxa de reação cruzada entre as estirpes PAL3, PAL5 e PRJ2 (Figuras 1, 2 e 3). As maiores variações foram observadas em relação aos anti-soros UAP-Ac7 e PRC1, isolados de abacaxi e P. purpureum, respectivamente, reconhecendo pouco os isolados da mesma espécie provenientes de cana-de-açúcar.

As estirpes UAP-Ac7 e PRC1 apresentaram menores valores de reação cruzada com os anti-soros produzidos. O anti-soro PRC1 foi o que apresentou menor similaridade com os isolados de G. diazotrophicus, porém esta estirpe é a mais distante quando avaliada pela análise de polimorfismo de enzimas comuns do metabolismo microbiano (Caballero-Mellado \& MartínezRomero, 1994), podendo explicar o baixo reconhecimento da estirpe PRC1 da mesma espécie, isolada de $P$. purpureum, com os isolados de cana-de-açúcar. Este anti-soro apresentou reação cruzada de $50 \%$ com a estirpe M130 da espécie Burkholderia spp., sendo que comportamento semelhante já havia sido detectado por Silva (1999), durante a caracterização de soros produzidos contra as estirpes PAL3 e PAL5.

As reações dos anti-soros PAL3 e PAL5 com os isolados testados estão de acordo com os resultados de Stephan et al. (1995), já que, quando um isolado reagia

Tabela 1. Relação das bactérias usadas nos testes de especificidade dos anticorpos produzidos contra Gluconacetobacter diazotrophicus e seus respectivos dados ecológicos.

\begin{tabular}{|c|c|c|c|c|}
\hline Estirpe $^{(1)}$ & Espécie & Local de isolamento & Associação & Parte da planta \\
\hline $\mathrm{M} 130^{\mathrm{T}}$ & Burkholderia sp. & Brasil & Arroz & Raiz \\
\hline $\operatorname{PPe} 8^{\mathrm{T}}$ & B. tropica & Brasil & Cana-de-açúcar & Raiz \\
\hline $\mathrm{Y}^{\mathrm{T}}$ & Azospirillum amazonense & Brasil & Trigo & Raiz \\
\hline $\mathrm{Sp} 7^{\mathrm{T}}$ & A. brasilense & Brasil & Digitaria sp. & Raiz \\
\hline Sp59 & A. lipoferum & Brasil & Trigo & Raiz \\
\hline HRC54 & Herbaspirillum seropedicae & Brasil & Cana-de-açúcar & Raiz \\
\hline $\mathrm{Z} 67^{\mathrm{T}}$ & H. seropedicae & Brasil & Arroz & Raiz \\
\hline M4 ${ }^{\mathrm{T}}$ & H. rubrisubalbicans & Brasil & Cana-de-açúcar & Folhas \\
\hline HCC103 & H. rubrisubalbicans & Brasil & Cana-de-açúcar & Colmo \\
\hline PAL5 & Gluconacetobacter diazotrophicus & Brasil & Cana-de-açúcar & Colmos \\
\hline PAL3 & G. diazotrophicus & Brasil & Cana-de-açúcar & Colmos \\
\hline $\mathrm{PRJ}^{\mathrm{T}}$ & G. diazotrophicus & Brasil & Cana-de-açúcar & Raízes \\
\hline $\mathrm{PPe} 4$ & G. diazotrophicus & Brasil & Cana-de-açúcar & Raízes \\
\hline PRC1 & G. diazotrophicus & Brasil & Pennisetum purpureum & Colmos \\
\hline UAP Ac7 & G. diazotrophicus & México & Abacaxi & Pseudocaule \\
\hline LMG $1262 \mathrm{t} 2^{\mathrm{T}}$ & G. pasteurianus & $-(2)$ & Cerveja & $-(3)$ \\
\hline LMG $1527^{\mathrm{T}}$ & G. hansenii & $-(2)$ & Vinagre & $-(3)$ \\
\hline LMG $1261 \mathrm{t} 1^{\mathrm{T}}$ & G. aceti & $-(2)$ & Vinagre & $-(3)$ \\
\hline ATCC 33424 & Frateuria aurantia & $-(2)$ & $-(2)$ & $-(3)$ \\
\hline
\end{tabular}

${ }^{(1)}$ T: estirpe tipo. ${ }^{(2)}$ Desconhecido. ${ }^{(3)}$ Não-determinado. 
com o anti-soro PAL3, o mesmo não ocorria com o antisoro PAL5 e, quando era reconhecido por este último, apresentava níveis insignificantes de reação com o antisoro PAL3.

Um maior número de isolados obtidos de variedades de cana-de-açúcar provenientes da coleção de germoplasma de Campos dos Goytacazes, RJ, foi reconhecido pelo anti-soro PAL3. Os isolados que reagiram com o anti-soro PAL3 eram provenientes da parte aé- rea e das raízes. Stephan (1995) não encontrou esta estirpe na parte aérea de cana-de-açúcar, sugerindo que a similaridade dos lipopolissacarídeos com polissacarídeos capsulares poderia gerar um estímulo de defesa do vegetal, impedindo o estabelecimento da bactéria.

$\mathrm{O}$ anti-soro UAP-Ac7, produzido a partir de isolado de G. diazotrophicus retirado de planta de abacaxi, pareceu ser comum aos produzidos a partir de isolados de cana-de-açúcar, já que reconheceu a maioria dos isola-

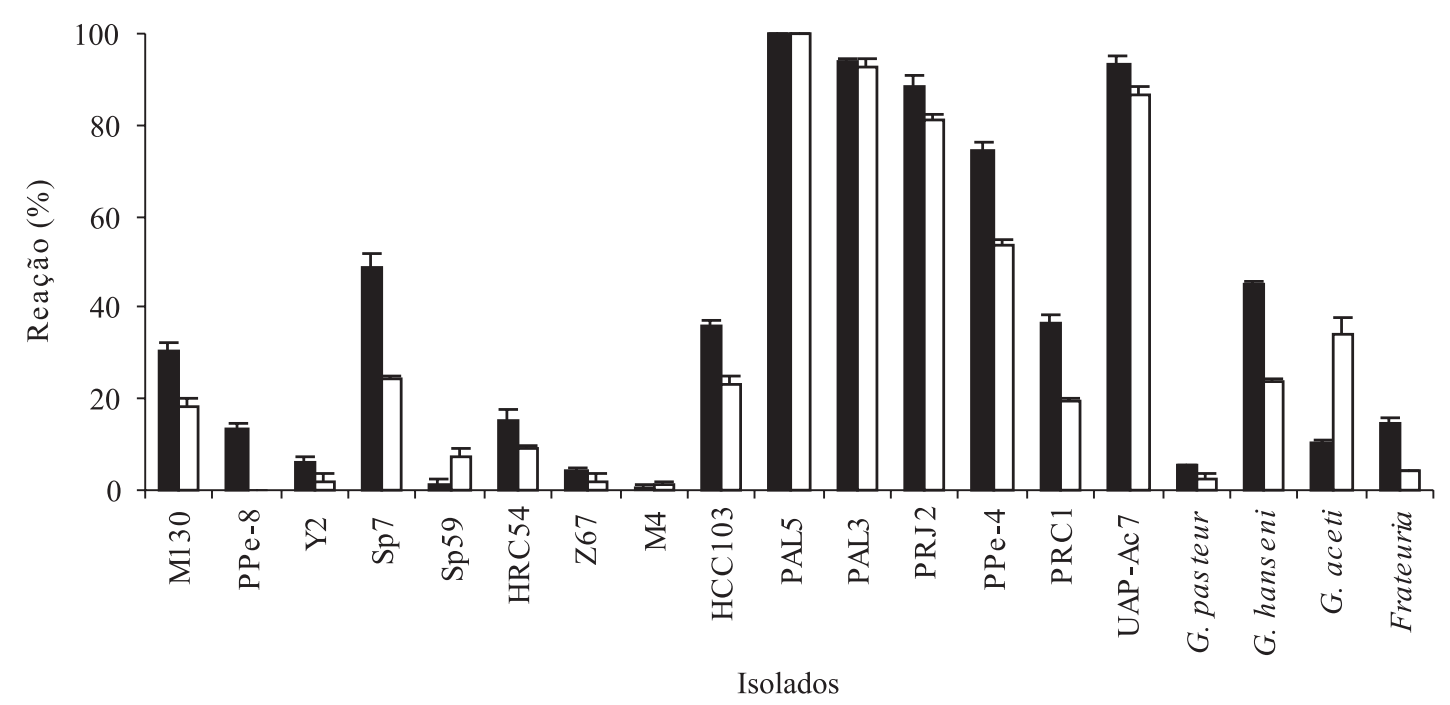

Figura 1. Especificidade do soro produzido contra a estirpe padrão de Gluconacetobacter diazotrophicus, PAL5, isolada de cana-de-açúcar. Anti-soro primário e pré-imune sem purificação diluído 1:1000 (口) e purificado 1:10 em PBS $(\square)$, anticorpo secundário diluído 1:1000. Barras em cada coluna representam o desvio-padrão da média.

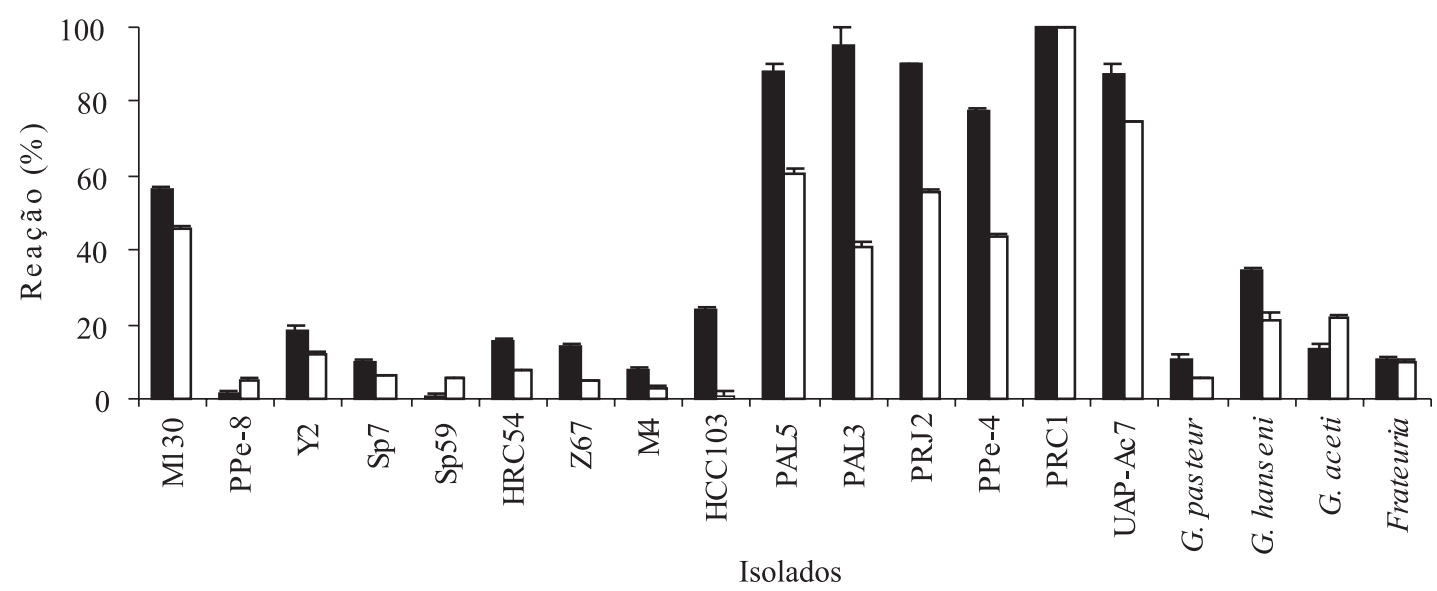

Figura 2. Especificidade do soro produzido contra a estirpe padrão de Gluconacetobacter diazotrophicus, PRC1, isolada de $P$. purpureum. Anti-soro primário e pré-imune sem purificação diluído 1:1000 (ם) e purificado 1:10 em PBS $(\square)$, anticorpo secundário diluído 1:1000. Barras em cada coluna representam o desviopadrão da média. 
dos. Porém PRC1, isolado de P. purpureum, reconheceu poucos isolados, confirmando os resultados de CaballeroMellado et al. (1995), que verificaram, mediante o uso de MLEE, que este isolado era o mais distante.

A estirpe PAL3 é também considerada uma estirpe rara (Caballero-Mellado \& Martínez-Romero, 1994) e o reconhecimento dos isolados apenas pelo anti-soro produzido contra esta estirpe foi determinante na formação dos pequenos grupos de isolados, que apresentaram maior distância em relação aos dois grandes grupos, sendo que a maioria foi isolada da coleção de germoplasma de Camamu, BA (Figura 4). Estes resultados e os altos valores de reação dos isolados de café com anti-soros de estirpes de cana-de-açúcar demonstram que provavelmente não há especificidade de hospedeiro em relação a G. diazotrophicus.

Em dendrograma obtido a partir dos resultados de porcentagem de reação pela técnica de ELISA em relação ao controle positivo, dos 140 isolados de G. diazotrophicus retirados da parte aérea e do sistema radicular de variedades de cana-de-açúcar, foi observado a formação de dois grandes grupos, englobando os padrões da espécie e os isolados de café, abacaxi e $P$. purpureum, que diferem a um nível de $35 \%$, e 12 isolados mais distantes, formando pequenos grupos que chegaram a 68\% de diferença (Figura 4). Observou-se que os isolados de diferentes variedades, espécies e partes da planta de cana-de-açúcar, provenientes de inúmeros países, distribuem-se aleatoriamente ao longo do dendrograma.

Houve um claro agrupamento em relação à coleção de germoplasma, indicando, pela técnica de ELISA, que o ambiente apresentou maior influência sobre a diversidade da população, ao passo que o efeito da espécie ou variedade de cana-de-açúcar parece não ser claro (Figura 5). Resultados semelhantes foram obtidos por Reis Junior et al. (2004) estudando a diversidade de isolados de Azospirillum spp. em associação com Brachiaria spp. Neste caso a técnica de ELISA revelou que o local do experimento teve grande influência sobre a diversidade dos isolados. Estes resultados são considerados comuns e esperados, pois caracteres fenotípicos que atuam como determinantes antigênicos, como lipopolissacarídeos e proteínas de membrana, sofrem grande influência de fatores ambientais, como grau de aeração, teores de ferro, e outros (Davies \& Quirie, 1996).

Estes grupos, que diferem a um nível de $35 \%$ englobando os isolados das diferentes coleções de germoplasma, podem estar relacionados à quantidade de nitrogênio $(\mathrm{N})$ aplicado. O primeiro grupo é formado pela maioria dos isolados de variedades provenientes de Camamu, BA, as quais receberam $82 \mathrm{~kg} \mathrm{ha}^{-1} \mathrm{de} \mathrm{N}$, no momento do plantio, e $202 \mathrm{~kg} \mathrm{ha}^{-1} \mathrm{de} \mathrm{N}$ adicionados anualmente, em contraste com Campos dos Goytacazes, RJ, cujas variedades não receberam nenhuma aduba-

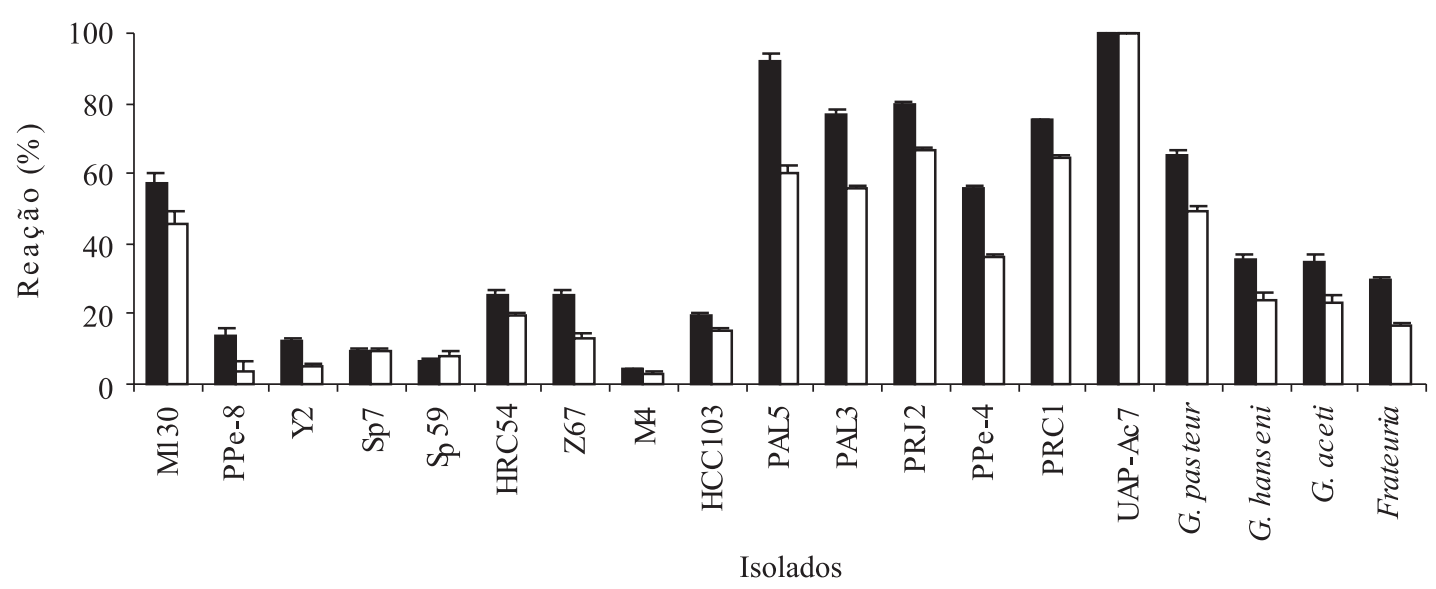

Figura 3. Especificidade do soro produzido contra a estirpe padrão de Gluconacetobacter diazotrophicus, UAP-Ac7, isolada de abacaxi. Anti-soro primário e pré-imune sem purificação diluído 1:1000 ( $\square$ ) e purificado 1:10 em PBS ( $\square$ ), anticorpo secundário diluído 1:1000. Barras em cada coluna representam o desviopadrão da média. 
ção nitrogenada. Altas aplicações de fertilizantes nitrogenados já foram sugeridas como responsáveis pela diminuição do número populacional de G. diazotrophicus em variedades de cana-de-açúcar cultivadas no México (Fuentes-Ramírez et al., 1999), Índia (Muthukumarasamy et al., 1999), Filipinas (Gonzalez \& Barraquio, 2000) e Brasil (Reis Junior et al., 2000). Posteriormente foi observado que íons amônio inibem o cultivo deste organismo dentro dos tecidos de cana-de-açúcar (Muthukumarasamy et al., 2002). Caballero-Mellado \& Martínez-Romero (1994) e Caballero-Mellado et al.
(1995) consideram que a fertilização química pode limitar a diversidade genética desta população.

Em virtude da variabilidade observada na identificação de G. diazotrophicus pela técnica de ELISA, foi proposto um estudo com primer espécie-específico visando confirmar que os isolados testados pertencem a esta espécie. Todos os isolados selecionados amplificaram com o iniciador espécie-específico AD, de G. diazotrophicus e não amplificaram com os primers espécie-específicos nas duas novas espécies de Gluconacetobacter, associadas a plantas de café cultivado no México, indicando que de fato pertencem à espécie G. diazotrophicus.

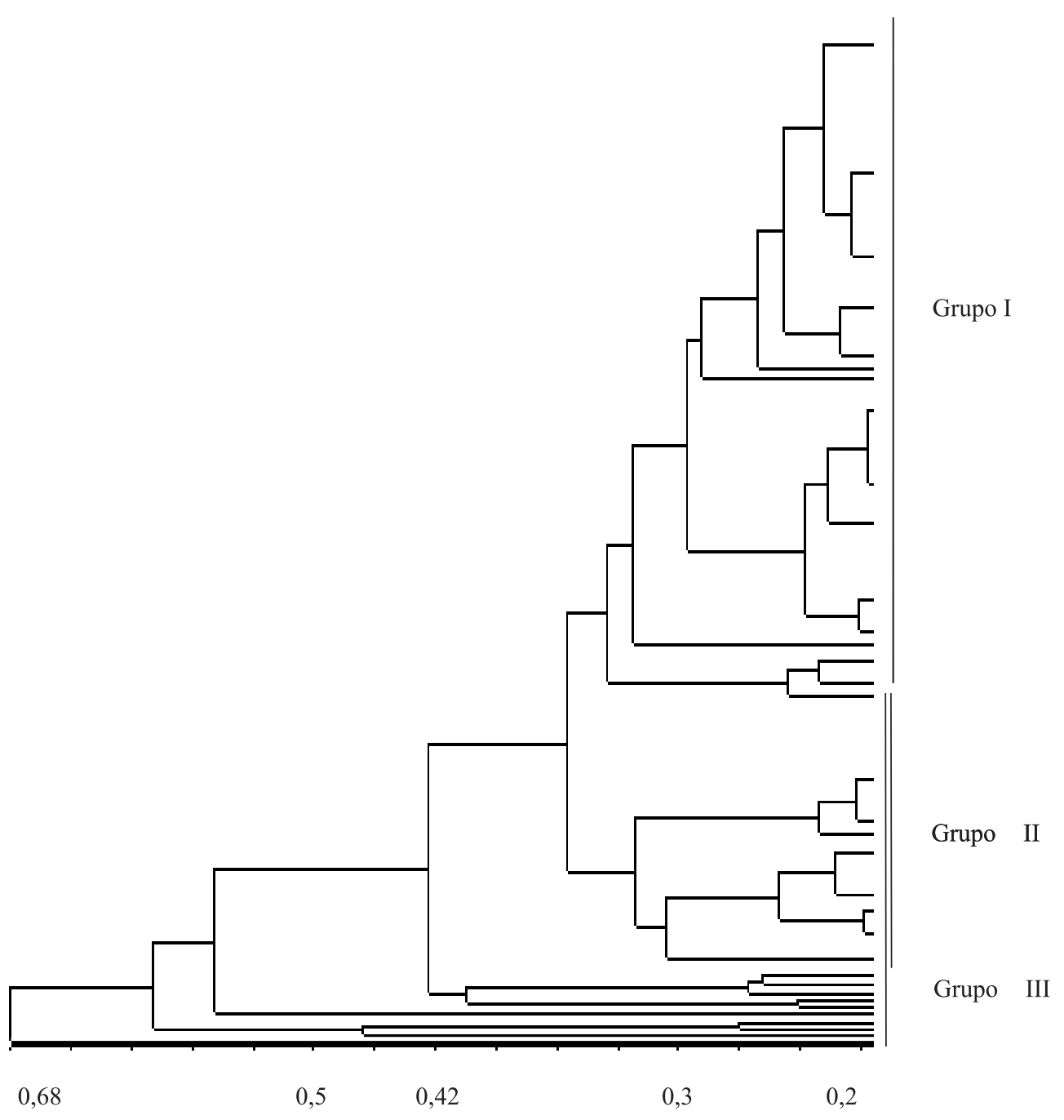

Figura 4. Dendrograma de distância dos isolados de Gluconacetobacter diazotrophicus obtidos de variedades de cana-de-açúcar mantidas nas coleções de germoplasma de Campos dos Goytacazes, RJ, e de Camamu, BA, e estirpes padrões da mesma espécie, a partir do índice Bray Curts e do método UPGMA. Grupo I e III, Camamu, BA; Grupo II, Campos dos Goytacazes, RJ. 


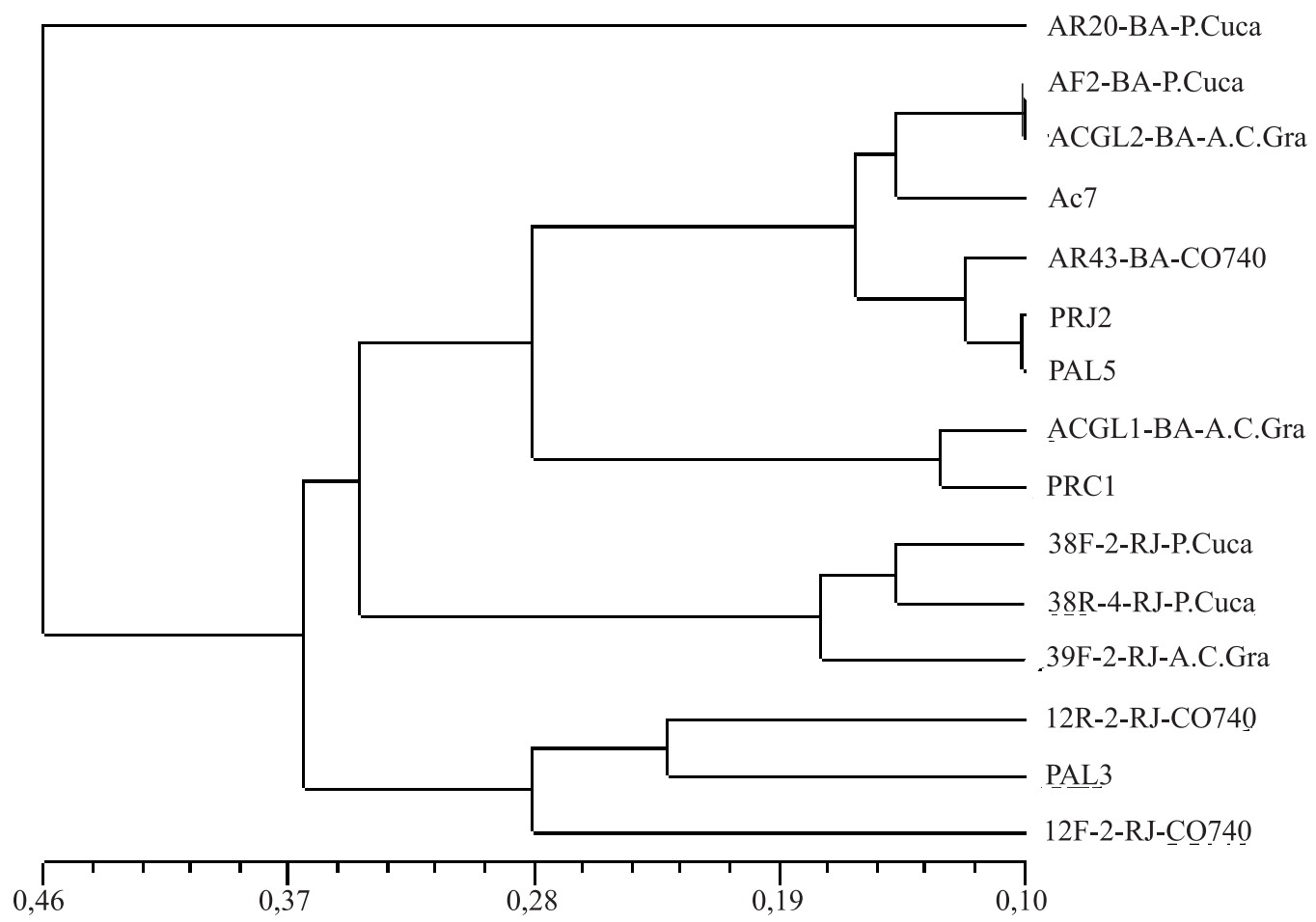

Figura 5. Dendrograma de distância dos isolados de Gluconacetobacter diazotrophicus obtidos de variedades de cana-de-açúcar mantidas nas coleções de germoplasma de Campos dos Goytacazes, RJ e de Camamu, BA e estirpes padrões da mesma espécie, a partir do índice Bray Curts e do método UPGMA. Variedades P.Cuca: Pepe Cuca, originária de Cuba; CO740: CO740, Índia e A.C. Gra: Azul Casa Grande, Peru.

\section{Conclusões}

1. Dois grandes grupos de isolados de Gluconacetobacter diazotrophicus formaram-se com distância de 35\% entre si, utilizando a reação imunológica medida pela técnica de ELISA indireto.

2. O agrupamento dos isolados não está relacionado com a espécie de planta, variedade de cana-de-açúcar, parte da planta e origem da variedade.

3. Altas doses de nitrogênio levam à diminuição da diversidade de G. diazotrophicus.

4. Todos os isolados testados pertencem à espécie G. diazotrophicus.

\section{Agradecimentos}

Ao programa PRONEX II número 76971051 00, pelo financiamento parcial do trabalho; à UFRRJ e Embrapa Agrobiologia, pelo apoio físico; à Capes, pela bolsa de mestrado concedida ao primeiro autor.

\section{Referências}

AUDY, P.; BRAAT, C.E.A.; SAINDON, G.; HUANG, H.C.; LAROCHE, A. A rapid and sensitive PCR-based assay for concurrent detection of bacteria causing common and halo blights in bean seed. Phytopathology, v.86, p.361-366, 1996.

CABALLERO-MELLADO, J.; FUENTES-RAMÍREZ, L.E.; REIS, V.M.; MARTÍNEZ-ROMERO, E. Genetic structure of Acetobacter diazotrophicus populations and identification of a new genetically distant group. Applied and Environmental Microbiology, v.61, p.3008-3013, 1995.

CABALLERO-MELLADO, J.; MARTÍNEZ-ROMERO, E. Limited genetic diversity in the endophytic sugarcane bacterium Acetobacter diazotrophicus. Applied and Environmental Microbiology, v.60, p.1532-1537, 1994.

CAVALCANTE, V.A.; DÖBEREINER, J. A new acid tolerant nitrogen-fixing bacterium associated with sugarcane. Plant and Soil, v.108, p.23-31, 1988.

DAVIES, R.L.; QUIRIE, M. Intra-specific diversity within Pasteurella trehalosi based on variation of capsular polysaccharide, lipopolysaccharide and outer-membrane proteins. Microbiology, v.142, p.551-560, 1996.

FUENTES-RAMÍREZ, L.E.; BUSTILLOS-CRISTALLES, R.; TAPIA-HERNANDEZ, A.; JIMÉNEZ-SALGADO, T.; WANG, 
E.T.; MARTÍNEZ-ROMERO, E.; CABALLERO-MELLADO, J. Novel nitrogen-fixing acetic acid bacteria Gluconacetobacter johannae sp. nov. and Gluconacetobacter azotocaptans sp. nov. associated with coffee plants. International Journal of Systematic and Evolutionary Microbiology, v.51, p.1305-1314, 2001.

FUENTES-RAMÍRES, L.E.; CABALLERO-MELLADO, J.; SEPÚLVEDA, J.; MARTÍNEZ-ROMERO, E. Colonization of sugarcane by Acetobacter diazotrophicus is inhibited by high $\mathrm{N}$-fertilization. FEMS Microbiology Ecology, v.29, p.117-128, 1999.

FUENTES-RAMÍREZ, L.E.; JIMÉNEZ-SALGADO, T.; ABARCA-OCAMPO, I.R.; CABALERO-MELLADO, J. Acetobacter diazotrophicus, an indole-acetic producing bacterium isolated from sugarcane cultivars of Mexico. Plant and Soil, v.154, p.145-150, 1993.

GONZALEZ, M.S.; BARRAQUIO, W.L. Isolation and characterization of Acetobacter diazotrophicus in Saccharum officinarum L., Saccharum spontaneum L., and Erianthus sp. The Philippine Agricultural Scientist, v.83, p.173-181, 2000.

GRAY, T.R.G; MANSOOR, E.Y. The application of serological techniques to the taxonomy of Arthrobacter and related organisms. Microbiology, v.142, p.561-573, 1996.

KIRCHHOF, G.; BALDANI, J.I.; REIS, V.M.; HARTMANN, A. Molecular assay to identify Acetobacter diazotrophicus and detect its occurrence in plant tissues. Canadian Journal of Microbiology, v.44, p.12-19, 1998.

LOMMEL, S.A.; McCAIN, A.H.; MORRIS, T.J. Evaluation of indirect enzyme-linked immunosorbent assay for the detection of plant viruses. Phytopathology, v.72, p.1028-1022, 1982.

MUTHUKUMARASAMY, R.; REVATHI, G.; LAKSHMINARASIMHAN, C. Influence of nitrogen fertilization on the isolation of Acetobacter diazotrophicus and Herbaspirillum spp. from Indian sugarcane varieties. Biology and Fertility Soils, v.29, p.157-164, 1999.

MUTHUKUMARASAMY, R.; REVATHI, G.; SESHADRI, S.; LAKSHMINARASIMHAN, C. Gluconacetobacter diazotrophicus (syn. Acetobacter diazotrophicus), a promising diazotrophic endophyte in tropics. Current Science, v.83, p.137-145, 2002.

MUTHUKUMARASAMY, R.; REVATHI, G.; VADIVELU, M. Antagonistic potential of $\mathrm{N}_{2}$-fixing Acetobacter diazotrophic against Colletotrichum falcatum Went.: a causal organism of red-rot of sugarcane. Current Science, v.78, p.1063-1065, 2000.

PIÑON, D.; CASAS, M.; BLANCH, M.; FONTANIELLA, B.; BLANCO, Y.; VICENTE, C.; SOLAS, M.T.; LEGAZ, M.E. Gluconacetobacter diazotrophicus, a sugar cane endosymbiont, pro- duces a bacteriocin against Xanthomonas albilineans, a sugar cane pathogen. Research in Microbiology, v.153, p.345-351, 2002.

REIS, V.M.; CRUZ, G.B.; FERREIRA, A.; FERREIRA, M.; FERREIRA, A.C.; REIS, F.B.; ASSIS, J.R.; SALLES, J.F.; WEBER, O.B. Produção e caracterização de soros policlonais para a detecção de bactérias diazotróficas. Seropédica: Embrapa-CNPAB, 1997. 11p. (Documentos, 30).

REIS, V.M.; OLIVARES, F.L.; DÖBEREINER, J. Improved methodology for isolation of Acetobacter diazotrophicus and confirmation of its endophytic habitat. World Journal of Microbiology and Biotechnology, v.10, p.401-405, 1994.

REIS JUNIOR, F.B.; SILVA, L.G.; REIS, V.M.; DÖBEREINER, J. Ocorrência de bactérias diazotróficas em diferentes genótipos de cana-de-açúcar. Pesquisa Agropecuária Brasileira, v.35, p.985994, 2000.

REIS JUNIOR, F.B.; SILVA, M.F. da; TEIXEIRA, K.R.S.; URQUIAGA, S.; REIS, V.M. Intra-specific diversity study of the nitrogen fixing bacterium Azospirillum amazonense isolated from different Brachiaria species. Symbiosis, v.36, p.41-56, 2004.

RIBEIRO, J.R. A aplicação da técnica de ELISA no estudo ecológico de Rhizobium sp. isolados de nódulos de caupi (Vigna unguiculata (L.) Walp.) originários da região nordeste brasileira. 1999. 117p. Dissertação (Mestrado) - Universidade Federal do Rio de Janeiro, Rio de Janeiro.

ROHLF, F.J. NTSYS-pc: numerical taxonomy and multivariate analysis system. Setauket: State University of New York, 2000. 37p.

SILVA, L.G. Estudos de colonização em cana-de-açúcar (Saccharum officinarum) por Acetobacter diazotrophicus e Herbaspirillum spp. utilizando técnicas imunológicas. 1999, 152p. Dissertação (Mestrado) - Universidade Federal Rural do Rio de Janeiro, Seropédica.

STEPHAN, M.P. Caracterização imunoquímica e bioquímica dos polissacarídeos da superfície celular da bactéria fixadora de nitrogênio Acetobacter diazotrophicus. 1995. 124p. Tese (Doutorado) - Universidade Federal do Rio de Janeiro, Rio de Janeiro.

STEPHAN, M.P.; FONTAINE, T.; PREVIATO, J.O.; MENDONÇA PREVIATO, L. Differentiation of capsular polysaccharides from Acetobacter diazotrophicus strains isolated from sugarcane. Microbiology and Immunology, v.39, p.237-242, 1995.

TAPIA-HERNANDEZ, A.; BUSTILLOS-CRISTALES, M.R.; JIMÉNEZ-SALGADO, T.; CABALLERO-MELLADO, J.; FUENTES-RAMÍREZ, L.E. Natural endophytic occurrence of Acetobacter diazotrophicus in pineapple plants. Microbial Ecology, v.39, p.45-55, 2000.

Recebido em 22 de outubro de 2003 e aprovado em 4 de maio de 2004

Pesq. agropec. bras., Brasília, v.39, n.8, p.763-770, ago. 2004 